\title{
Enhanced Performance of Matrix Converter using Adaptive Computing Techniques
}

\author{
${ }^{1}$ A.Sreenivasulu , ${ }^{2}$ D.Venkata Brahma Naidu, ${ }^{3}$ J.N.Chandra Sekhar \\ $1 \& 3$ IEEE Member, ${ }^{2}$ Dept. Of EEE,SVUCE,Tirupati. \\ sreenivasulu136@gmail.com,dvb.naidupeed@gmail.com,chandu.jinka@gmail.com
}

\begin{abstract}
This paper deals mainly with the improvement of linear load current profile considering different grid conditions. A popular power conversion circuit known to be a Matrix Converter was considered to study the effects on the quality of electrical power supply. This advanced converter configured with power semiconductor devices effectively optimizes the harmonic components of linear type loads with the aid of various controllers like PI, Fuzzy, Adaptive Fuzzy and ANFIS models. The simulation studies and subsequent comparisons are derived for the proposed system on MATLAB/SIMULINK package under balanced and distorted grid conditions.

Keywords: Power Quality, Matrix Converter, Venturini Modulation, Adaptive Fuzzy Controller, ANFIS, Linear Load, Total Harmonic Distortion, Balanced grid, Distorted grid.
\end{abstract}

\section{INTRODUCTION}

Due to subsequent developments in the field of power semiconductor technology adaptability of the electrical power system to the dynamic load requirements is enhanced. Frequent variations on the supply and load side affect the parameters like service continuity, frequency, transient voltages and currents. Power conversion methods provide an optimal solution to ensure a proper and efficient operation of the electrical system. In the late 1970's Gyugyi proposed a direct ac-ac frequency converter. Thereafter Static power frequency converters were considered of which indirect ac-ac converter with PWM-VSI became predominant. Due to the uncontrolled action of diode bridge rectifier in the converter, the currents on the input side contain harmonics which creates distortion in the input line voltages [1].

Later a high frequency based matrix converter operated with ideal transformer was presented by Venturini [2]. Subsequently Venturini modulated matrix converter configured using classical PI controller was introduced to minimize the effects of the distorted input line voltages [7]. Further to enhance the matrix converter efficiency a good compensated Fuzzy system based controller was proposed [8]. Then a PI based Fuzzy controller was implemented to mitigate the harmonic effects produced by different non-linear loads [9].

In this paper, the operational ability of the Matrix converter is observed with linear load for undistorted grid and distorted grid cases. Various controller models like PI, Fuzzy, Adaptive Fuzzy and ANFIS were applied to the proposed model. The effective operation of Matrix converter is assessed by observing the linear load current waveform with minimum harmonic content.

\section{OPERATION AND MODULATION OF MATRIX CONVERTER \\ 2.1 Operating Principle}

Basically the circuit of a matrix converter comprises of one level converter arranged with an array of $\mathrm{m} \times \mathrm{n}$ bilateral power semiconductor switches to connect, directly, an m-phase voltage supply to $\mathrm{n}$-phase linear load.

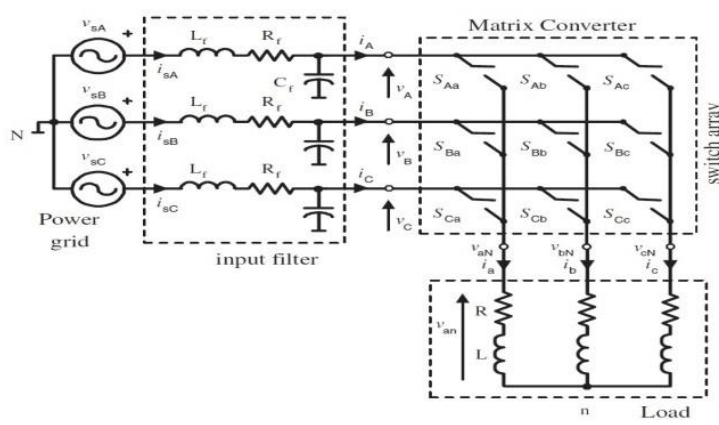

Fig 2.1. Circuit of Matrix Converter

From the above circuit diagram the matrix converter consists of the supply voltages, supply currents and the output load voltages w.r.t to the neutral point of the load $n$.Each switch $S_{p q}(t), \mathrm{p}=$ $\{\mathrm{A}, \mathrm{B}, \mathrm{C}\}$ and $\mathrm{q}=\{\mathrm{a}, \mathrm{b}, \mathrm{c}\}$ can connect or disconnect phase $p$ of the input side to phase $q$ of the load side and, with possible combination of the conduction periods of these switches, output voltages $\mathrm{v}_{\mathrm{pN}}$ can be calculated. 
Each switch is described by a switching model, defined as:

$S_{p q}(t)=0$ if $S_{p q}$ is in open condition $S_{p q}(t)=1$

if $S_{p q}$ is in closed condition -(1)

$S_{A p}+S_{B p}+S_{C p}=1$ where $p=A, B, C$ and

$q=a, b, c$

To implement the modulation schemes the following equations (3) and (4) are significant. These equations describe the possible switching combination of open and closed switches to produce the required output load voltages.

$\left[\begin{array}{c}v_{a N}(t) \\ v_{b N}(t) \\ v_{C N}(t)\end{array}\right]=\left[\begin{array}{lll}S_{A a}(t) & S_{B a}(t) & S_{C a}(t) \\ S_{A b}(t) & S_{B b}(t) & S_{C b}(t) \\ S_{A c}(t) & S_{B c}(t) & S_{C c}(t)\end{array}\right]\left[\begin{array}{l}v_{A}(t) \\ v_{B}(t) \\ v_{C}(t)\end{array}\right](3)$ $\left[\begin{array}{l}i_{A}(t) \\ i_{B}(t) \\ i_{C}(t)\end{array}\right]=\left[\begin{array}{lll}S_{A a}(t) & S_{B a}(t) & S_{C a}(t) \\ S_{A b}(t) & S_{B b}(t) & S_{C b}(t) \\ S_{A c}(t) & S_{B c}(t) & S_{C c}(t)\end{array}\right]\left[\begin{array}{l}i_{a}(t) \\ i_{b}(t) \\ i_{c}(t)\end{array}\right](4)$

The input source currents are represented by a filter model with an array of switched input currents. This model is derived on the assumption that $V_{s p}=V_{p}$ which stands important for implementing modulation schemes.

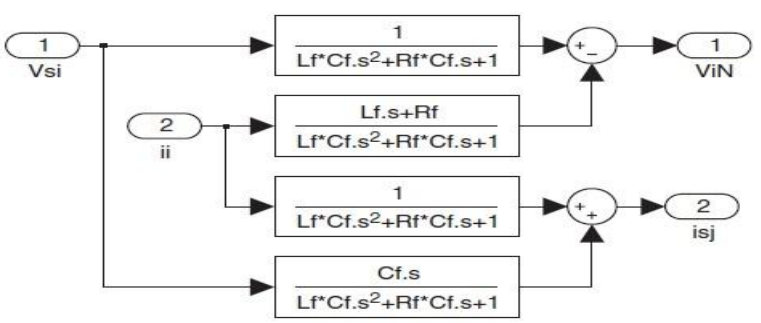

Fig 2.2. Filter model for input voltages

\subsection{Venturini Modulation Method}

Among the available modulation techniques, Venturini modulation method is implemented for the matrix converter. This modulation scheme provides the simple synthesis of low frequency components of output load voltages and input source currents with instantaneous magnitudes of input source voltages and output load currents respectively. The modulation algorithm represented is suitable for real time implementation but in practice it is not used due to the $50 \%$ voltage transfer ratio limitation [1].

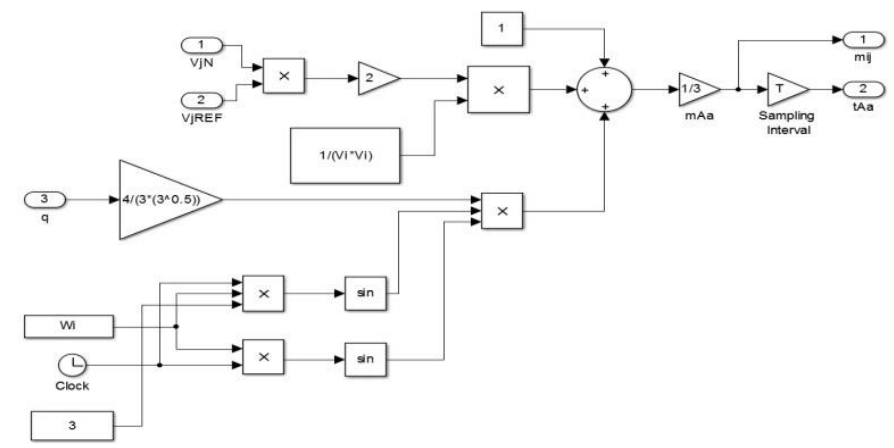

Fig 2.3. Generation of duty cycle for matrix converter

\section{CONFIGURABLE CONTROLLERS 3.1 PI Controller}

A Closed loop arrangement of matrix converter using PI controller is presented inn Figure 3.1. The momentary magnitude of the error can be determined from the differences observed between the instantaneous current-space-vector Iwhich is sensed by the measured $3-\propto$ output load current of the matrix converter and the reference current-space-vector $I_{\text {ref }}[7]$.

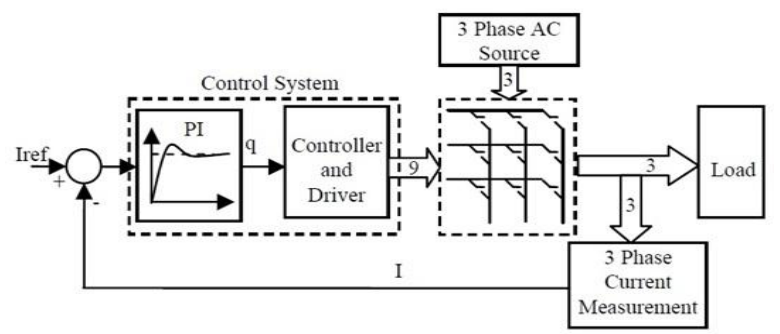

Fig 3.1. Closed loop matrix converter with PI controller

\subsection{Fuzzy Logic Controller}

A fuzzy logic controller based feedback system for a matrix converter is shown in Fig. 3.2. In this model also the error term can be calculated by considering the measured value of $I$ and the reference-current-space-vector $I_{r e f}$.

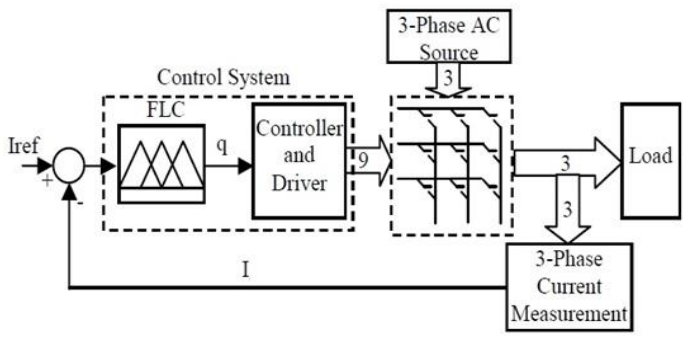

Fig. 3.2. Fuzzy model for matrix converter

\subsection{Adaptive Fuzzy Controller}

Based on the working abilities and control features of matrix converter, an Adaptive Fuzzy control technique is developed and represented in Figure 3.3. 


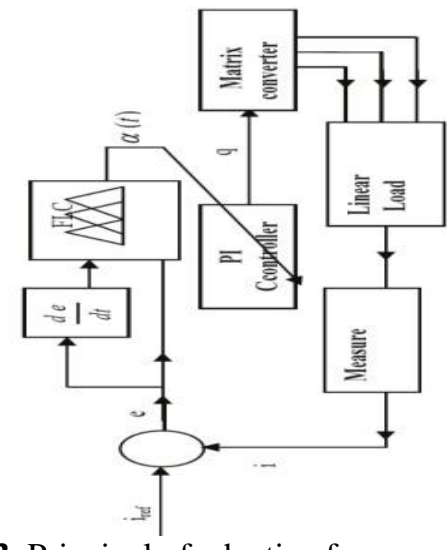

Fig 3.3. Principal of adaptive fuzzy controller

A traditional PI controller is used in combination with a fuzzy logic control system. From the obtained error signal and its time derivative, the fuzzy system adapts continuously the suitable parameters of the PI controller to extract the better operational features [9]. For the fuzzy controller system the error and its derivative are considered as the input quantities. The corrected instantaneous error $\mathrm{e}(t)$ can be determined from the resultant of measured current value and its reference value .

\subsection{ANFIS controller}

ANFIS controller is basically a hybrid computing model comprising a suitable kind of artificial neural network which is based on T-S fuzzy inference method. This model introduced in the early decade of 1990 s is able to provide good solutions for most of the non-linear systems. In this model the inference engine represent to a suitable set of fuzzy if-then rule which have adaptive learning capability in optimizing the nonlinear crctem modele [11]

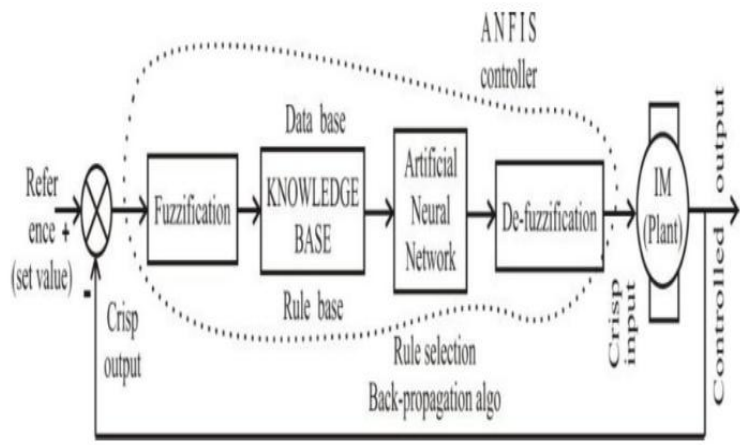

Fig. 3.4. ANFIS model for matrix converter

\section{SIMULATION AND RESULTS}

Adaptive fuzzy controller is a hybrid controller which incorporates the features of both PI and fuzzy logic controllers [9]\&[10]. The simulink model of adaptive fuzzy controller is shown below.

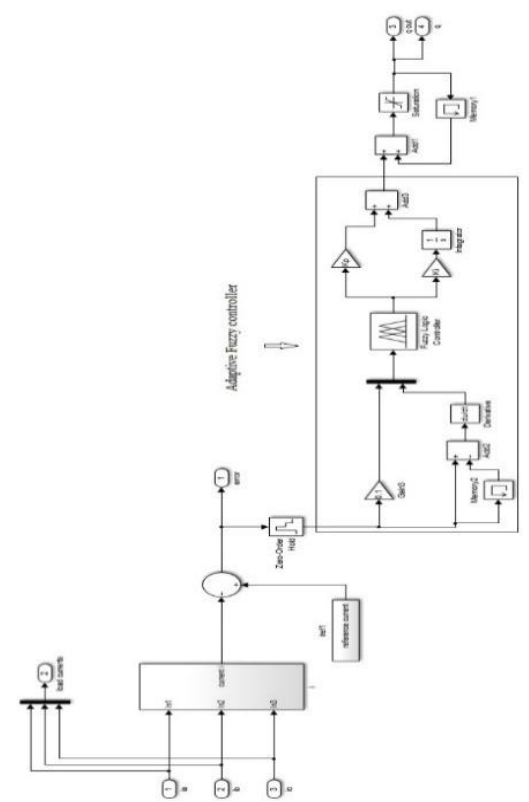

Fig. 4.1. Simulink model for adaptive fuzzy control based matrix converter

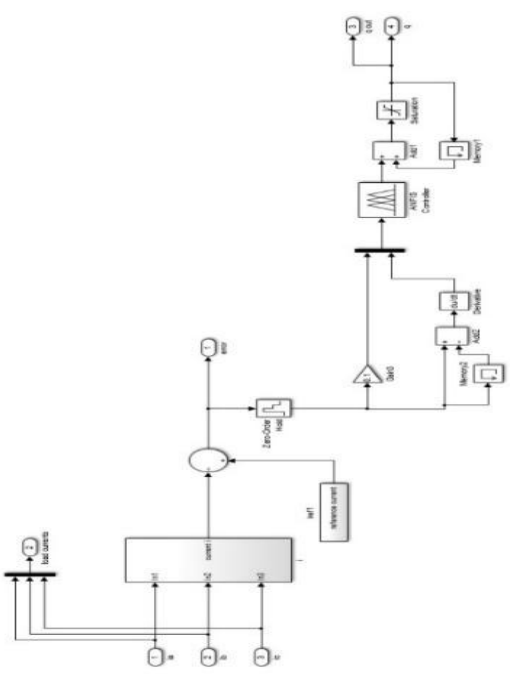

Fig. 4.2. Simulink model of ANFIS controller based matrix converter

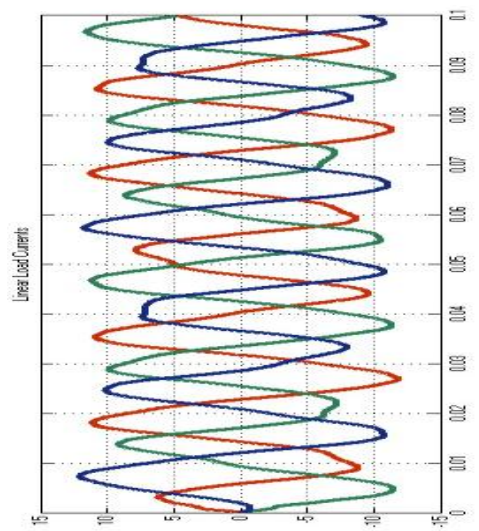

Fig. 4.3. Profile of Linear Load Current for Adaptive Fuzzy based matrix converter 


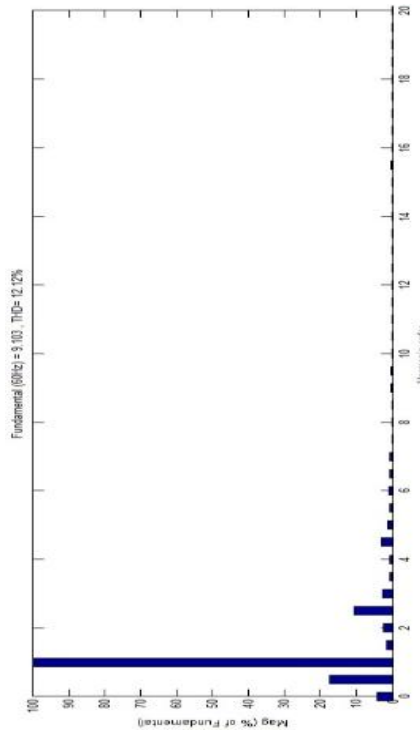

Fig. 4.4. Harmonic Spectrum of Linear Load current for Adaptive Fuzzy based matrix converter

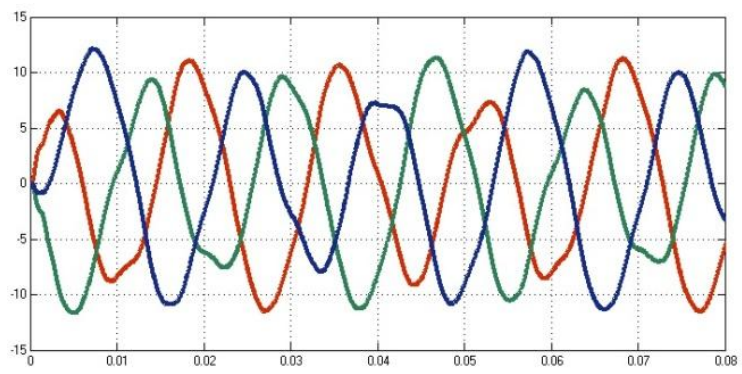

Fig. 4.5. Profile of Linear Load Current for ANFIS based matrix converter

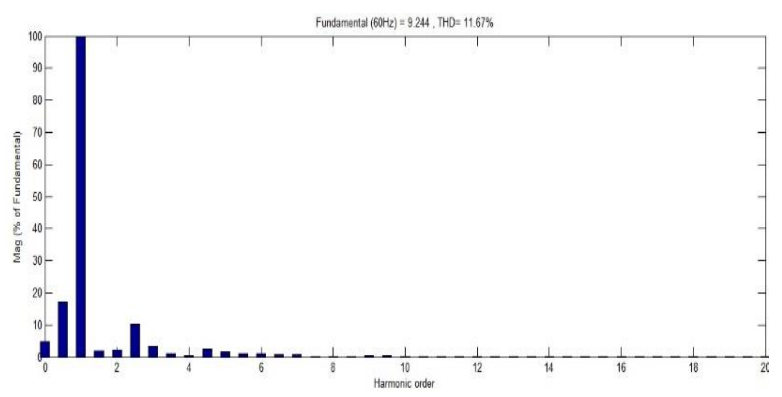

Fig. 4.6. Harmonic Spectrum of Linear Load current for ANFIS basedmatrix converter

Table 1: Comparison table for linear load currents in terms of THD

\begin{tabular}{|l|l|l|l|l|}
\hline \multirow{2}{*}{$\begin{array}{c}\text { Supply at } \\
\begin{array}{c}\mathbf{6 0 H z} \\
\text { frequency }\end{array}\end{array}$} & PI & Fuzzy & $\begin{array}{l}\text { Adaptiv } \\
\text { e Fuzzy }\end{array}$ & ANFIS \\
\hline $\begin{array}{l}\text { Undistort } \\
\text { ed Grid } \\
\text { Case }\end{array}$ & $12.00 \%$ & $8.49 \%$ & $6.22 \%$ & $6.04 \%$ \\
\hline $\begin{array}{l}\text { Distorted } \\
\text { Grid Case }\end{array}$ & $14.29 \%$ & $12.80 \%$ & $12.12 \%$ & $11.67 \%$ \\
\hline
\end{tabular}

V. CONCLUSION

In order to observe the effective operation and modulation schemes of the matrix converter, various control methods like PI, Fuzzy, Adaptive Fuzzy and ANFIS are duly implemented using MATLAB/SIMULINK tool. The simulation results display the linear load current profile when these control methods are used during distorted and undistorted grid cases along with its THD values shown in Table 1. From the obtained results conclusions can be drawn towards ANFIS controller for its better performance as it significantly improves the nature of linear load currents when compared to all other methods.

\section{REFERENCES}

[1] Arevalo.S.L,"Matrix Converter for Frequency Changing Power Supply Applications," Ph.D Thesis from University of Nottingham, January 2008.

[2] M. Venturini, "A new sine wave in, sine wave out converter technique eliminates reactive elements," Proceedings of POWERCON 7, pp. 310 - 315, 1980.

[3] J. Rodriguez, E. Silva, F. Blaabjerg, P. Wheeler, J. Clare, J. Pontt, "Matrix Converter Controlled with the Direct Transfer Function Approach: Analysis, Modelling and Simulation", Taylor\&Francis-International Journal of Electronics, vol. 92, no. 2, pp. 6385,February 2005.

[4] M. Venturini and A. Alesina, "The generalised transformer: new bidirectional sinusoidal waveform frequency converter with continuously adjustable input power factor', in Conf. Rec. IEEE PESC'80, pp. 242-252.

[5] S. M. Barakati, Modeling and Controller Design of a Wind Energy Conversion System Including a Matrix Converter, thesis of Doctor of Philosophy in Electrical and Computer Engineering Waterloo, Ontario, Canada, 2008.

[6] Luca Zarri. Control of Matrix Converters. $P h$. D. in Electrical Engineering XIX year power electronics, machines and drives 
(ING-IND/32), University of Bologna. 2007.

[7] H. Karaca, R. Akkaya, Control of Venturini Method Based Matrix Converter in Input Voltage Variations, Proceedings of the International MultiConference of Engineersand Computer Scientists,Hong Kong 2009 Vol II IMECS 2009, March 18 $-20,2009$.

[8] Hulusi Karaca, Student Member, IEEE, Ramazan Akkaya, Hüseyin Do an. A Novel Compensation Method Based on Fuzzy Logic Control for Matrix Converter under Distorted Input Voltage Conditions.Proceedings of the 2008 International Conference onElectrical Machines, 2008.

[9] A. Boukadoum, T. Bahi, S. Oudina, Y. Souf A, and S. Lekhchine, "Fuzzy controladaptive of a matrix converter for harmonic compensation caused by nonlinear loads," Energy Procedia 18, pp $715-723,2012$.

[10] B.Hamane, M. L. Doumbia, A. Cheriti and K. Belmokhtar, Comparative Analysis of PI and Fuzzy Logic Controllers for Matrix Converter, IEEE Ninth International Conference on Ecological Vehicles and Renewable Energies (EVER), 2014.

[11] Chitra Venugopal, ANFIS Based Field Oriented Control for Matrix Converter fedInduction Motor, 2010IEEE international conference on power and energy, kualalampur,Malaysia, December 2010.

[12] IEEE Standard 519-1992, IEEE recommended practices and requirements for harmonic control in electrical power systems," IEEE Std 519-1992, 12 April.1993. 